\title{
Comparison of lymphatic vessel density and expression of VEGF-C and VEGF-D lymphangiogenic factors in Warthin's tumours and oncocytic adenomas
}

\author{
Jiri Hoza ${ }^{a}$, Richard Salzmana ${ }^{\mathrm{a}}$ Tomas Bakaj ${ }^{\mathrm{a}}$, Ladislava Kucerova ${ }^{\mathrm{b}}$, Ivo Starek ${ }^{\mathrm{a}}$
}

\begin{abstract}
Objectives. To compare the density of lymphatic vessels and VEGF-C and VEGF-D expression in Warthin's tumours (WTs) and oncocytic adenomas (OCAs).

Methods. Twenty three WTs and 13 OCAs of the parotid gland were analyzed. Lymphatic vessels were detected using the D2-40 antibody. For evaluation of the intratumour and peritumour lymphatic vessel density (iLVD and pLVD, respectively) the area of greatest vascularisation (hot spots) was chosen, using a $\times 40$ field, and the number of vessels per square millimeter was counted in a $\times 200$ field. The staining intensity for VEGF-C and VEGF-D immunoreaction in the tumour cells was graded from 0 to 3.

Results. The mean iLVD and pLVD values in WTs was 4.7 (range 1-8) and 6.9 (range 3-10), those in the OCAs 1.0 (range $0-3$ ) and 5.8 (range 2-8), respectively. The differences in the iLVD, but not pLVD between the two tumour groups were statistically significant. In both entities, the pLVD markedly outnumbered the iLVD. The intratumour vessels in the WTs were present exclusively in the lymphoid stroma. In the group of 23 WTs, $13(56.6 \%), 17(73.9 \%)$ and $10(43.4 \%)$ samples revealed positive VEGF-C, VEGF-D and both immunoreactions, respectively. 10 of 13 (77\%) cases revealed VEGF-D immunoreaction and in none of them was the VEGF-C reaction present.

Conclusion. The tumours had a comparable high density of peritumorous lymphatic network. However, WTs markedly differed from OCAs in the number of the intratumorous vessels. These were abundant solely in the stroma of WT, while practically lacking in the neoplastic epithelium of the WT and relatively rare in OCAs. We suggest that homeostasis in both entities is mediated mainly by peritumorous lymphatics. The lymphatic drainage in WTs is also fostered exclusively by stromal lymphatics, whereas in stroma poor OCAs by the vessels present in their neoplastic epithelium. We also believe that WTs stimulate proliferation of pre-existing lymphatic capillaries by means of the paracrine secretion of VEGF-C and VEGF-D in the neoplastic as well as reactive stromal cells, while in the OCAs only the latter factor takes part in their lymphangiogenesis.
\end{abstract}

Key words: lymphatic vessel density, oncocytoma, Warthin's tumor, salivary gland

Received: April 5, 2017; Accepted with revision: October 25, 2017; Available online: November 2, 2017 https://doi.org/10.5507/bp.2017.048

${ }^{a}$ Department of Otorhinolaryngology, University Hospital Olomouc and Faculty of Medicine and Dentistry, Palacky University Olomouc, Czech Republic

${ }^{b}$ Department of Molecular Pathology, University Hospital Olomouc and Faculty of Medicine and Dentistry, Palacky University Olomouc, Czech Republic

Corresponding author: Tomas Bakaj, e-mail: tomas.bakaj@fnol.cz

\section{INTRODUCTION}

Lymphatic vessels play an important role in tissue homeostasis, inflammations, regeneration and wound healing. They also serve as conduits by which tumour cells colonize regional lymph nodes and hence invade the blood circulation. Formation, growth and function of lymphatic vasculature are promoted by many cytokines among which vascular endothelial factor C (VEGF-C) and D (VEGF-D) are crucial ${ }^{1}$. These two ligands activate tyrosine kinase vascular endothelial growth factor receptor-3 (VEGFR-3) of lymphatic endothelial cells ${ }^{2}$. In this way, the intracellular transduction cascade is launched, resulting in their blockage of apoptosis, proliferation and migration ${ }^{3,4,5}$. The sources of lymphangiogenous factors in tumours are neoplastic cells. Recently, it has been demonstrated, that in some carcinomas, including those originating in the head and neck region, forced VEGF-C and -D expression and density of associated newly formed lymphatic network are significant predictors of nodal involvement and prognosis ${ }^{6-23}$.

Particular histopathologic types of salivary carcinomas show different propensity to nodal metastasis ${ }^{24}$. This, along with the relative scarcity of these tumours is probably the reason why little attention has been paid to their lymphangiogenesis so far. Mello et al. ${ }^{25}$ in 75 various salivary carcinomas found both intratumorous and peritumorous lymphatic vessels. Consequently, he concluded that lymphangiogenesis occurred in these malignancies. On the other hand, in the Fujita's ${ }^{26}$ series of 29 salivary adenoid cystic carcinomas only sparse peritumourous but no intratumorous lymphatics were seen, implying this entity was incapable of stimulating their formation. Their findings are in contradiction with our previous study demonstrating the presence and prognostic relevance of the latter channels in adenoid cystic carcinomas $^{27}$. Soares et al. ${ }^{28}$ assumed that intratumorous lymphatics represented an additional pathway increasing 
the metastatic potential in widely invasive carcinoma ex pleomorphic adenoma.

In some malignant and also benign salivary neoplasms, expression of vascular endothelial growth factor (VEGF) was detected ${ }^{29,30,31}$. This cytokine (now referred to as VEGF-A) belongs (along with the VEGF-B, VEGF-C and VEGF-D) to the superfamily of platelet-derived growth factor. It is known to induce active proliferation not only of tumour associated blood but also lymphatic vessels ${ }^{32}$. A number of authors have confirmed the prognostic relevance of VEGF expression and associated density of blood microvessels in various tumours ${ }^{33-36}$. However, the reported VEGF expression and its correlation with lymph nodes metastasis and prognosis of salivary carcinomas is controversial $^{37-43}$.

In general, information on the lymphatic network in benign tumours is rather sporadic. Not surprisingly, it is especially valid for relatively uncommon salivary gland adenomas. Of these mainly pleomorphic adenomas have been analyzed. Neither primary nor recurrent lesion showed any intratumorous lymphatics ${ }^{44,45}$. Remarkably, Soares et al. ${ }^{46}$ demonstrated significantly higher density of the intratumorous lymphatic network in basal cell adenomas than that of pleomorphic adenoma. Up to now, only one paper was found on the lymphatics in Warthin's tumour (WT), revealing a rich lymphatic network in the lymphoid component, exceeding that in the adjacent parotid parenchyma and lymph nodes ${ }^{47}$. The authors concluded that the formation of lymphatic microvessels was stimulated by the epithelial cells of that entity. However, in their study, no relevant lymphangiogenic factors were tested.

As VEGF-C and VEGF-D are believed to be essential in the process of tumour lymphangiogenesis (vide supra), the purpose of this study was to compare the expression of these factors and lymphatic environment in WT and the monomorphic oncocytic adenoma (OCA). Both benign lesions are composed of oxyphyllic ductal cells. However, they differ from each other in architecture and stromal abundance. While in WT, the epithelium is arranged in double rows and the number of stroma individually varies, the cells in oncocytomas show solid, trabecular or tubular formations with practically absent stroma. Moreover, the former tumour is completely free of neoplastic myoepithelial cells, whereas in the latter they may be very sparsely scattered.

\section{MATERIAL AND METHODS}

In the WT group, 2 females and 17 males, aged from 46 to 82 (mean 65.4) years, were enrolled. Two of the 19 patients presented with bilateral double and single tumours, respectively. A total of 23 WT were thus analyzed. All tumours originated in the parotid tail. Surgical treatment consisted of simple enucleation (10 pts.), partial (7 pts.) or (in a patient with multiple lesion) of superficial parotidectomy.

In the OCA group, 13 cases ( 5 females and 8 males, aged from 55 to 75 , mean 61years) were analyzed. Except for one deep lobe case, all tumours were localized in the superficial part of the parotid. In 10 and 3 patients partial and superficial parotidectomies, respectively, were performed.

\section{VEGF-C AND VEGF-D IMMUNOHISTOCHEMISTRY}

Sections of $4 \mu \mathrm{m}$ thickness were cut from each archived paraffin embedded tissue sample. The sections were deparaffinised and rehydrated in graded alcohol. Endogenous peroxidase was blocked in hydrogen peroxide for $15 \mathrm{~min}$. The sections were rinsed in distilled water and subsequently with Tris/Tween buffer. Anti-VEGF-C and anti-VEGF-D (Abcam, 330 Cambridge Science Park, Cambridge, United Kingdom, dilution 1:50 and 1:100, respectively) and the D2-40 anti-podoplanin (Dako Denmark, Produktionsvej 42, Glostrup, Denmark, dilution 1:100) antibodies were employed. Detection was achieved using the EnVision and Dual System HRP. Enzyme activity was visualized with diaminobenzidine tetrahydrochloride, and the sections were counterstained with haematoxylin. Positive controls were prepared according to the manufacturer's recommendations.

The staining intensity for VEGF-C and VEGF-D immunoreaction in the tumour cells was assessed as follows: the intensity equal to that of lymphatic endothelial cells as grade 2, absent, weaker, and stronger reactions as 0,1 , and 3 , respectively.

\section{Evaluation of lymphatic vascular density}

Lymphatic microvessels were identified through immunohistochemical staining using the D2-40 antibody. Observation of both intra- and peritumorous (i.e. in the capsule or in the tumour margins if the former was absent) vascularisation was performed throughout the whole specimen in all tissue samples. For evaluation of density, the area of the highest vascularisation (hot spots) was chosen, using a $\times 40$ field, and the number of vessels per square millimeter was counted in a $\times 200$ field.

\section{Statistical analysis}

For comparison of intratumorous and peritumorous lymphatic vessel density (iLVD and pLVD, respectively) within and between tumour groups paired t-tests were used. The analysis was performed with STATISTICA v. 10.0 (Statsoft Inc). A $P$ value of $<0.05$ was considered statistically significant.

\section{RESULTS}

\section{Lymphatic vessel density}

In WTs, lymphatic capillaries were demonstrated in the capsule (Fig. 1) and the lymphoid (Fig. 2) but not in the epithelial component. Moreover, there was a D2-40 positive reaction in basal epithelial cells and in follicular dendritic cells of the germinal centers in these entities (Fig. 2). Both peri- and intratumorous lymphatics were 
also seen in oncocytomas, the sparse myoepithelial cells of which also stained with the D2-40 antibody (Fig. 3). The mean iLVD and pLVD values in WTs were 4.7 (range $1-8$ ) and 6.9 (range 3-10), those in the OCAs 1.0 (range $0-3$ ) and 5.8 (range 2-8), respectively. The differences in the iLVD, but not pLVD between the two tumour groups were highly statistically significant. In both tumours, iLVD markedly outnumbered pLVD (Table1).

\section{VEGF-C AND VEGF-D IMMUNOHISTOCHEMISTRY}

In the group of 23 WTs, 13 (56.6\%) samples showed VEGF-C positivity. The immunoreaction was found in the nuclei of stromal lymphocytes, macrophages and on-

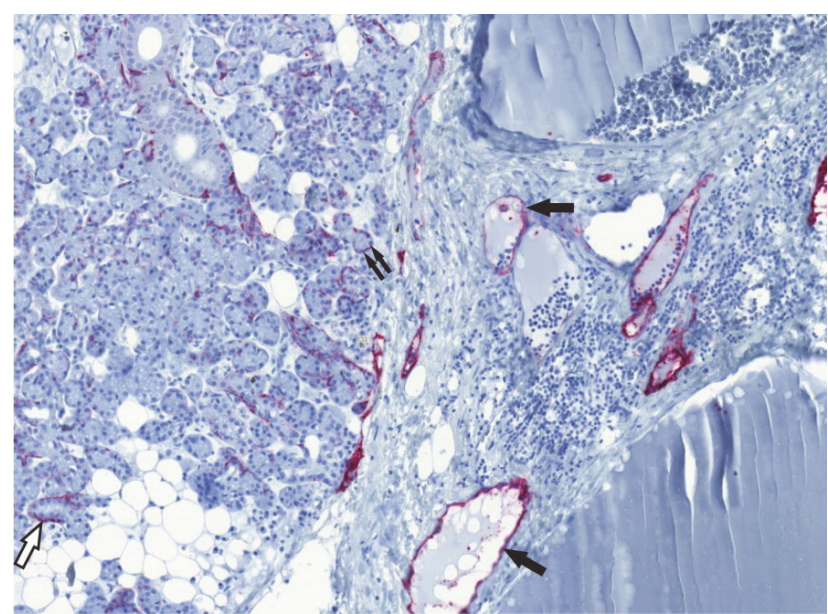

Fig. 1. Warthin's tumour.

Mostly dilated D2-40 positive lymphatic capillaries are seen in the capsule (black arrows). In the adjacent parotid parenchyma, myoepithelial cells around ducts (white arrow) and acini (double arrow) also stain positively.

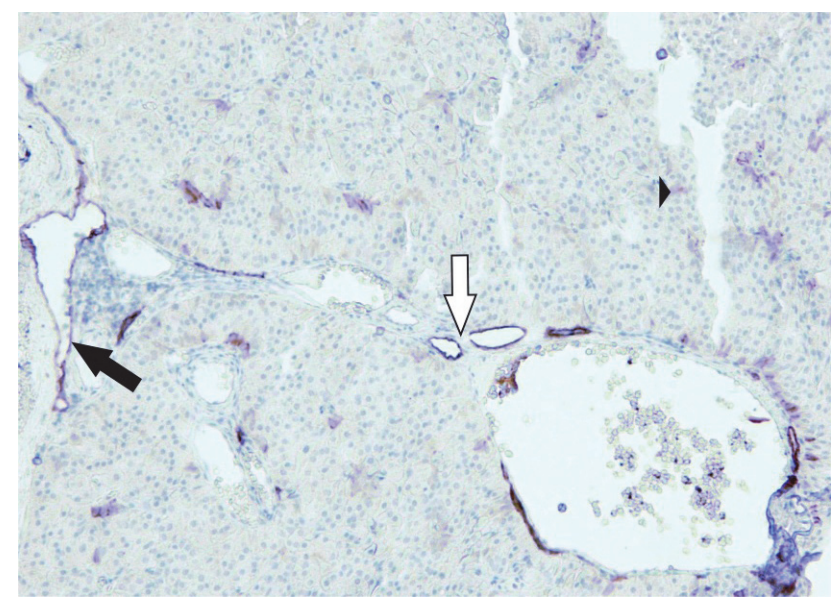

Fig. 3. Oncocytoma.

Dilated D2-40 positive lymphatic vessel (black arrow) is present in the tumour capsule. Two smaller channels are placed in the parenchyma (white arrow), in which faintly stained myoepithelial cells (arrowhead) are scattered.
Table 1. Values of iLVD, pLVD in WTs and OCAs.

\begin{tabular}{llll}
\hline & WTs & OCAs & \\
\hline iLVD & $4.7( \pm 2.1)$ & $1.0( \pm 1.3)$ & $P<0.001$ \\
pLVD & $6.9( \pm 2.2)$ & $5.8( \pm 1.5)$ & $P=0.10$ \\
& $P<0.001$ & $P<0.001$ & \\
\hline
\end{tabular}

cocytes. In some of the latter, cytoplasm immunoreaction was also focally present (Fig. 4). Seventeen (73.9\%) cases revealed VEGF-D immunoreaction in the nuclei of, lymphocytes, macrophages and oncocytic cells (Fig. 5). Ten (43.4\%) tumours showed simultaneous reactions. In the OCAs, there was no VEGF-C reaction. Ten of 13 cases $(77 \%)$ revealed moderate nuclear VEGF-D immunoreac-

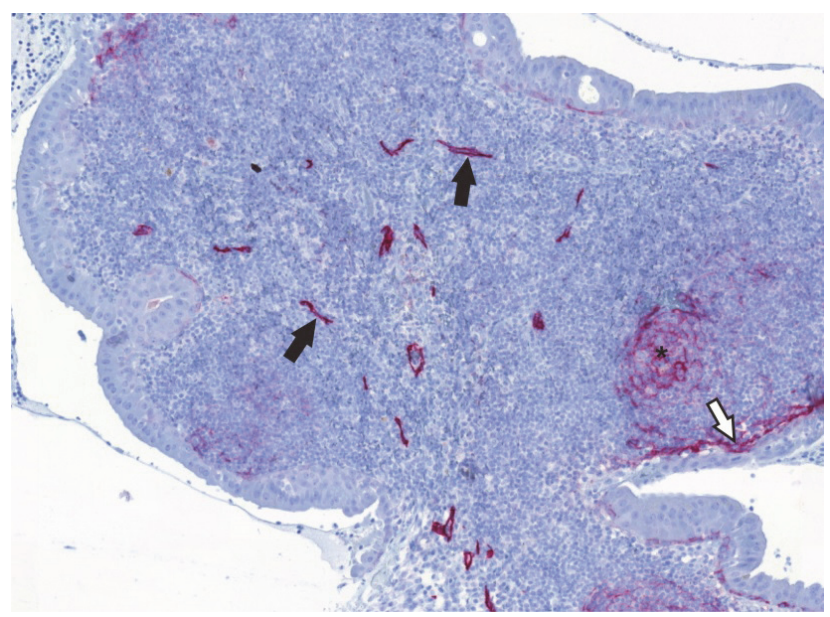

Fig. 2. Warthin's tumour.

Mostly compressed D2-40 positive lymphatic vessels are seen in the lymphoid stroma (black arrows). Positive immunoreaction reveal also follicular dendritic cells in the germinal center (asterisk) and basal cell of the epithelial component (white arrow).

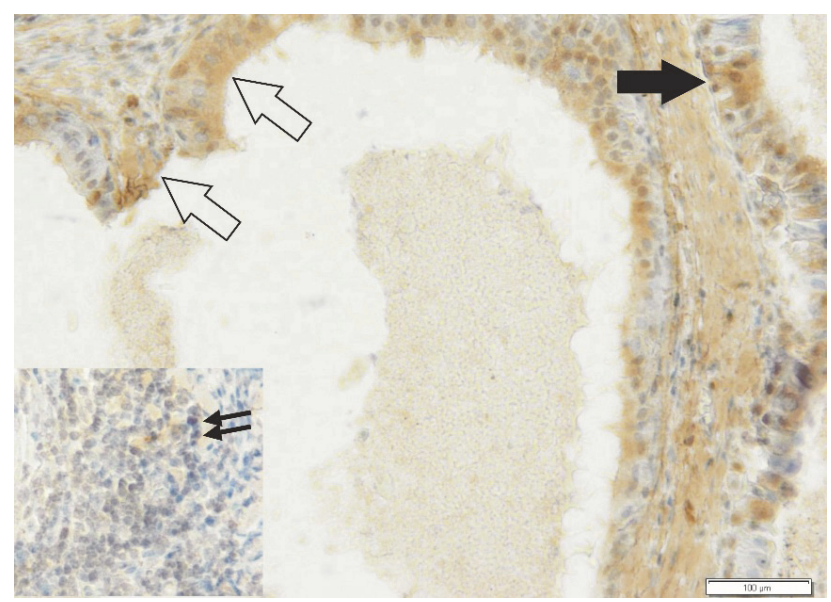

Fig. 4. Warthin's tumour.

Moderate VEGF-C immunoreaction is seen in the nuclei mostly of the inner layer of oncocytic cells (black arrow), some of which also show focally weak staining of the cytoplasma (white arrow). Inset: weak to moderate VEGF-C positivity in the nuclei of stromal lymphocytes (double arrow). 


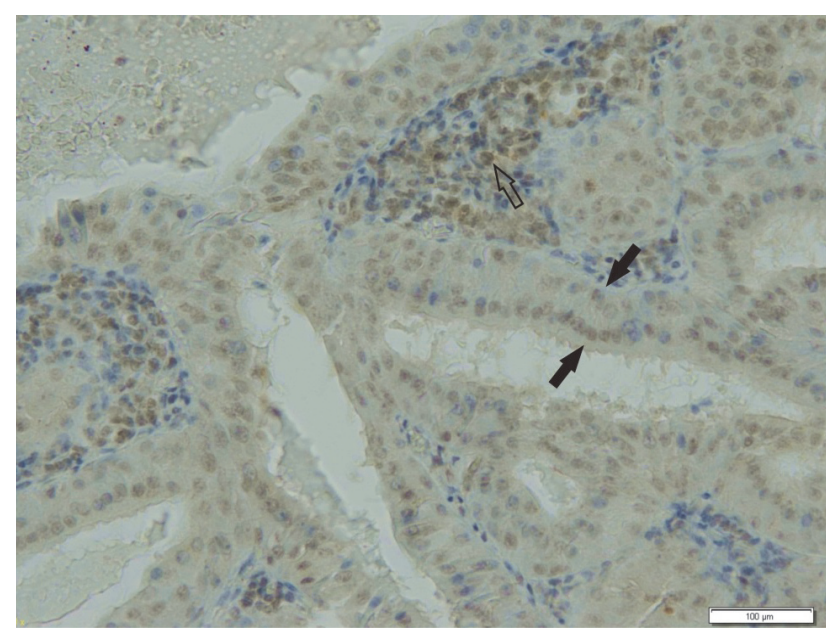

Fig. 5. Warthin's tumour.

Weak VEGF-D immunoreaction in the nuclei of both layers of some oncocytic cells (black arrow), moderate to strong nuclear positivity in stromal lymphocytes (white arrow).

tion of neoplastic cells, the cytoplasma of some of which showed very weak focal positivity (Fig. 6).

\section{DISCUSSION}

The relevance of expression of lymphangiogenic factors and associated lymphangiogenesis for nodal metastasis and the prognosis of many human carcinomas has been unequivocally documented ${ }^{7}$. Initially it was suggested that only peritumorous lymphatics were involved in the dissemination of neoplastic cells with other authors not finding functional intratumorous lymphatics in various tumours $^{23,48-51}$. However, recent research has shown that the latter channels may be present in some carcinomas, including those originating in the head and neck region ${ }^{52-55}$, thus contributing to the lymphatic spread of neoplastic cells. On the other hand, the role the lymphatics play in the viability of cells in malignant as well as benign tumours is not clear. These vessels are suggested to drain colloids from the tumours contributing thereby - along with blood vessels - to the establishment of a specific stromal microenvironment that fosters tumour growth ${ }^{2,56}$. We demonstrated, that in both the WTs and OCAs, there were peritumorous lymphatics of comparable, relatively high density. Their number was markedly greater than intratumorous ones. Analogic distribution of lymphatic network has been reported not only in WT (ref. ${ }^{47}$ ) but also in pleomorphic adenoma ${ }^{28,44}$ and basal cell adenoma ${ }^{46}$. In our cases of WT, the intratumorous lymphatics were seen solely in the lymphoid stroma. However, they were detected by Teymoortash et al. ${ }^{47}$ to be very thinly dispersed among and in close contact with the oncocytic cells of this entity. We found significant difference in the density of intratumorous capillaries of WTs and OCAs. They were numerous in the stroma of the former lesions, but very sporadic in the latter. Scarcity of these lymphatics has been reported in primary and recurrent pleomorphic ade-

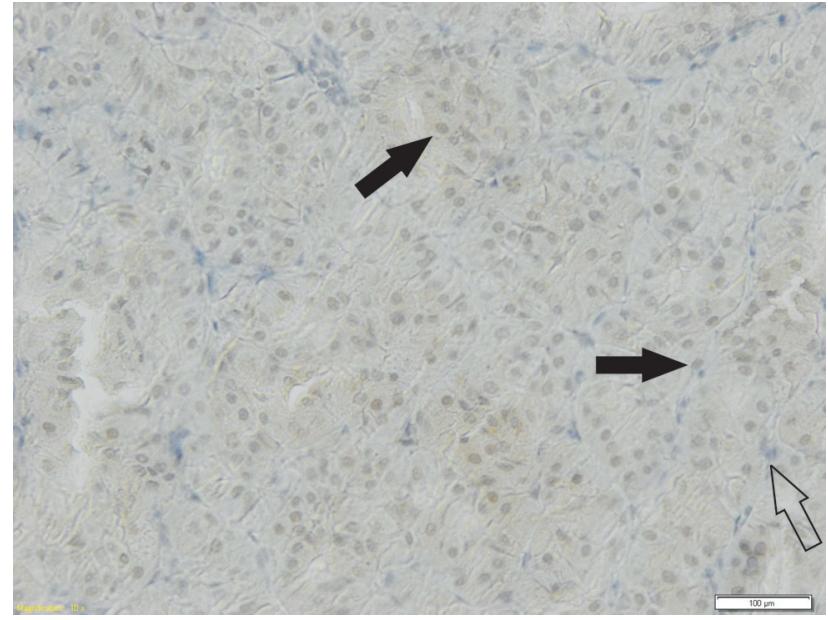

Fig. 6. Oncocytoma.

Moderate VEGF-D immunostaining in the nuclei of the majority of oncocytes (black arrow). Weak cytoplasmatic reaction is focally present in some cells. Negatively stained cells are rare (white arrow).

nomas, too ${ }^{44,28}$. In basal cell adenoma, the number of intratumorous vessels was also shown to be low, but exceeding that in pleomorphic adenoma ${ }^{46}$. In general, the minimal number or even absence of intratumorous lymphatics is considered to be due to the growth of neoplastic cells that increases interstitial pressure, thereby collapsing and/or pushing these vessels to the tumour periphery ${ }^{57,58}$. Soares et al. ${ }^{45}$ suggested that in pleomorphic adenomas, the analogic effect was exerted by their abundant myxochondroid stroma. In this study, the majority of WTs showed positivity of both VEGF-C and VEGF-D, while only the latter immunoreaction was present in the OCAs. Information regarding the expression of the major lymphangiogenic factors in salivary gland tumours is very limited. In our two previous papers, we demonstrated moderate to strong VEGF-C and VEGF-D immunoreactivity in all cell types of salivary adenoid cystic carcinomas ${ }^{27}$ and expression of only the latter cytokine in the cells of epithelial as well as mesenchymal component of pleomorphic adenomas ${ }^{44}$. Moreover, moderate expression of primarily haemangiogenic VEGF(A), known to cooperate with VEGF-C in the regulation of lymphangiogenesis ${ }^{59}$ was reported in the epithelial and some stromal lymphoid cells of WTs by Faur et al. ${ }^{29}$ and Nakamura et al. ${ }^{30}$. The last named authors could confirm VEGF immunoreactivity also in the epithelial and all phenotypic variants of neoplastic myoepithelial cells of pleomorphic adenoma. Similar results were published by Swelam et al. ${ }^{31}$, who suggested that the cells of pleomorphic adenoma produced VEGF for their own proliferation and that the strong expression of this cytokine was controlled by hypoxia. This conclusion was later confirmed by Soares et al. ${ }^{45}$. In their subsequent study ${ }^{46}$, these authors reported stronger VEGF immunoreactivity in basal cell adenoma than in pleomorphic adenoma. This finding corresponded to the markedly lower intratumorous lymphatic vessel density in the latter lesion. As it is evident from the presented and previously published studies $^{28,44,46}$, pleomorphic adenoma, oncocytic adenoma and 
basal cell adenoma reveal similar predominance of the peritumorous capillaries over the scarce intratumorous ones. This is not surprising considering that the latter are found in higher number only in some carcinomas, thus, increasing their metastatic capability. The explanation of the abundance of stromal lymphatics in WTs can be seen primarily in the plentitude and specific character of their stroma composed (i.a.) of lymphoid follicles containing lymphocytes and macrophages. In our study, both reactive cell types expressed either tested lymphangiogenic factors, stimulating in this way the proliferation of the pre-existing lymphatic vessels. The lymphangiogenetic role of macrophages in WT is further supported by Kerjaschki et al. ${ }^{60}$ who demonstrated that these cells are capable of direct trans-differentiation into endothelial cells and secretion of VEGF-C. Besides the cells of the epithelial component, moderate to strong expression of $\operatorname{VEGF}(\mathrm{A})$ was reported in the lymphocytes of WT (ref. ${ }^{29,30,61}$ ). The differences in intratumorous vessel density in WTs and other benign salivary adenomas probably also reflects their diverse biological character. While the latter are genuine neoplasms, the nature of WTs is a matter of controversy. Due to the demonstrated polyclonality of the oncocytic cells, this tumour is considered by some authors to be a tumour-like lesion $^{47,62}$. On the other hand, Rabia et al. ${ }^{63}$ and Nakamura et al. ${ }^{30}$ believe that Warthin's tumour represent a true neoplasm. Nonetheless, the oncocytic cells of either lesions evoke immunologic response in their stroma. This reaction may stimulate proliferation of lymphatic and blood vessels, similar to ordinary inflammatory conditions. This assumption seems to be supported by the analysis of blood vasculature in benign and malignant salivary tumours $^{29}$. Of these, the highest vascular density was found in WT. The OCAs and WTs have a very low proliferation rate of neoplastic cells, and the metabolic requirements of the tumours are thus minimal. Consequently, analogical density of the lymphatics in the neoplastic epithelium of both entities can be anticipated. However, in our study, their almost total absence in WTs contrasted to their occurrence in the OCAs. We, therefore, assume that in the latter entities these channels are responsible for maintaining their tumourous homeostasis, while in WTs it is mediated by stromal lymphatics.

\section{CONCLUSIONS}

Both tested tumours reveal comparable density of peritumorous lymphatic network, primarily providing their lymphatic drainage. However, WTs markedly differ from OCAs in the number of the intratumorous vessels. These are abundant solely in the stroma of WTs, while very rare in the neoplastic epithelium of the WTs and OCAs. Our results suggest that homeostasis in both entities is mediated primarily by peritumorous lymphatics. The lymphatic drainage in WTs is further fostered by stromal lymphatics, whereas in stroma poor OCAs by the vessels in their neoplastic epithelium. We also believe, that WTs stimulate proliferation of pre-existing lymphatic capillar- ies by means of the paracrine secretion of VEGF-C and VEGF-D in the neoplastic as well as reactive stromal cells, while in OCAs only the latter factor takes part in their lymphangiogenesis.

Acknowledgement: This study was supported by Ministry of Health, Czech Republic - conceptual development of research organization (FNOL, 0098892), RVO: 61989592. Mgr. Ing. Ivo Überall, Ph.D. is acknowledged for technical help in the manuscript preparation. Mr. George Kumsta is acknowledged for his help with the final English revision. Author contributions: JH: leading author, manuscript writing; RS: statistical analysis; TB: manuscript writing; LK, IS: histopathologic analysis.

Conflict of interest statement: The authors state that there are no conflicts of interest regarding the publication of this article.

\section{REFERENCES}

1. Cao Y. Opinion: emerging mechanisms of tumour lymphangiogenesis and lymphatic metastasis. Nat Rev Cancer 2005;5(9):735-43.

2. Tammela T, Alitalo K. Lymphangiogenesis: Molecular mechanisms and future promise. Cell 2010;140(4):460-76.

3. Achen MG, Jeltsch M, Kukk E, Mäkinen T, Vitali A, Wilks AF, Alitalo K, Stacker SA. Vascular endothelial growth factor D (VEGF-D) is a ligand for the tyrosine kinases VEGF receptor 2 (FIk1) and VEGF receptor 3 (Flt4). Proc Natl Acad Sci USA 1998;95(2):548-53.

4. Gerwins P, Sköldenberg E, Claesson-Welsh L. Function of fibroblast growth factors and vascular endothelial growth factors and their receptors inangiogenesis. Crit Rev Oncol Hematol 2000;34(3):185-94.

5. Kukk E, Lymboussaki A, Taira S, Kaipainen A, Jeltsch M, Joukov $\mathrm{V}$, Alitalo K. VEGF-C receptor binding and pattern of expression with VEGFR-3 suggests a role in lymphatic vascular development. Development 1996;122(12):3829-37.

6. Achen MG, McColl BK, Stacker SA. Focus on lymphangiogenesis in tumor metastasis. Cancer Cell 2005;7(2):121-7.

7. Alitalo K, Tammela T, Petrova TV. Lymphangiogenesis in development and human disease. Nature 2005;438(7070):946-53.

8. Audet N, Beasly NJ, MacMillan C, Jackson DG, Gullane PJ, KamelReid S. Lymphatic vessel density, nodal metastasis, and prognosis in patients with head and neck cancer. Arch Otolaryngol Head Neck Surg 2005;131(12):1065-70.

9. Beasly NJ, Prevo R, Banerji S, Leek RD, Moore J, van Trappen P, Cox G, Harris AL, Jackson DG. Intratumoral lymphangiogenesis and lymph node metastasis in head and neck cancer. Cancer Res 2002;62(5):1315-20.

10. Burian M, Quint C, Neuchrist C. Angiogenic factors in laryngeal carcinomas: do they have prognostic relevance? Acta Otolaryngol 1999;119(2):289-92.

11. Choi WW, Lewis MM, Lawson D, Yin-Goen Q, Birdsong GG, Cotsonis GA, Cohen C, Young AN. Angiogenic and lymphangiogenic microvessel density in breast carcinoma: correlation with clinicopathologic parameters and VEGF-family gene expression. Mod Pathol 2005;18(1):143-52.

12. Hu WG, Li JW, Feng B, Beveridge M, Yue F, Lu AG, Ma JJ, Wang ML, Guo Y, Jin XL, Zheng MH. Vascular endothelial growth factors $C$ and $D$ represent novel prognostic markers in colorectal carcinoma using quantitative image analysis. Eur Surg Res 2007;39(4):229-38.

13. Inoue K, Ozeki Y, Sugunuma T, Sugiura Y, Tanaka S. Vascular endothelial growth factor expression in primary esophageal squamous carcinoma. Cancer 1997;79(2):206-13.

14. Kitadai Y, Amioka T, Haruma K, Tanaka S, Yoshihara M, Sumii K, Matsutani N, Yasui W, Chayama K. Clinicopathological significance of vascular endothelial growth factor (VEGF)-C in human esophageal squamous cell carcinomas. Int J Cancer 2001;93(5):662-6.

15. Kyzas PA, Geleff S, Batistatou A, Agnantis NJ, Stefanou D. Evidence 
for lymphangiogenesis and its prognostic implications in head and neck squamous cell carcinoma. J Pathol 2005;206(2):170-7.

16. Mineta H, Miura K, Ogino T, Takebayashi S, Misawa K, Ueda Y, Suzuk I, Dictor M, Borg A, Wennerberg J. Prognostic value of vascular endothelial growth factor (VEGF) in head and neck squamous cell carcinomas. Br J Cancer 2000;83(6):775-81.

17. Moehler M, Frings C, Muller A, Gockel I, Schimanski CC, Biesterfeld S, Galle PR, Holtmann MH. VEGF-D expression correlates with colorectal cancer aggressiveness and is downregulated by cetuximab. World J Gastroenterol 2008;14(26):4156-67.

18. O-charoenrat $P$, Rhys-Evans $P$, Eccles SA. Expression of vascular endothelial growth factor family members in head and neck squamous cell carcinoma correlates with lymph node metastasis. Cancer 2001;92(3):556-68.

19. Salven P, Lymboussaki A, Heikkilä P, Jääskela-Saari H, Enholm B, Aase K, von Euler G, Eriksson U, Alitalo K, Joensuu H. Vascular endothelia growth factors VEGF-B and VEGF-C are expressed in human tumors. Amer J Pathol 1998;153(1):103-8.

20. Sedivy R, Beck-Mannagetta J, Haverkampf C, Battistutti W, Hönigschnabl S. Expression of vascular endothelial growth factor- $C$ correlates with the lymphatic microvessel density and the nodal status in oral squamous cell cancer. J Oral Pathol Med 2003;32(8):45560.

21. Tobler NE, Detmar M. Tumor and lymph node lymphangiogenesis - impact on cancer metastasis. J Leukocyt Biol 2006;80(4):691-6.

22. Tsurusaki T, Kanda S, Sakai H, Kanetake H, Saito Y, Alitalo K, Koji T. Vascular endothelial growth factor-C expression in human prostatic carcinoma and its relationship to lymph node metastasis. Br J Cancer 1999;80(1-2):309-13.

23. Xuan M, Fang YR, Wato M, Hata S, Tanaka A.Immunohistochemical co-localization of lymphatics and blood vessels in oral squamous cell carcinomas. J Oral Pathol Med 2005;34(6):334-9.

24. Spiro RH, Huvos AG, Strong EW. Cancer of the parotid gland: A clinicopathologic study of 288 primary cases. Am J Surg 1975;130(4):452 9.

25. Mello MF, Costa AF, Freitas LL, Soares AB, Araujo VC, Tincani AJ, Martins AS, Altemani A. Lymphatic vessel density and expressions of lymphangiogenic growth factors in salivary carcinomas. Neoplasma 2011;58(4):331-6.

26. Fujita G, Sato S, Kishino M, Iwai S, Nakazawa M, Toyosawa S, Yura Y, Ogawa Y. Lymphatic vessels and related factors in adenoid cystic carcinoma of the salivary gland. Mod Pathol 2011;24(7):885-91.

27. Starek I, Salzman R, Kučerová L, Skálová A, Hauer L. Expression of VEGF-C/-D and lymphangiogenesis in salivary adenoid cystic carcinoma. Pathol Res Pract 2015;211(10):759-65.

28. Soares AB, Ponchio L, Juliano PB, de Araújo VC, Altemani A. Lymphatic vascular density and lymphagiogenesis during tumor progression of carcinoma ex pleomorphic adenoma. J Clin Patho 2007;60(9):995-1000.

29. Faur AC, Lazar E, Cornianu M. Vascular endothelial growth factor (VEGF) expression and microvascular density in salivary gland tumors. APMIS 2014;122(5):418-26.

30. Nakamura Y., Yamamoto M, Sakamoto K, Ohta K, Umeda A, Tsukamoto T, Nakashima T. Growth factors, extracellular matrix components and cell adhesion molecules in Warthin's tumor. J. Oral Pathol Med 2001;30(5):290-5.

31. Swelam W, Ida-Yonemochi H, Maruyama S, Ohshiro K, Cheng J, Saku T. Vascular endothelial growth factor in salivary pleomorphic adenomas: one of the reasons for their poorly vascularized stroma. Virchows Arch 2005;446(6):653-62.

32. Hirakawa S, Kodama S, Kunstfeld R, Kajiya K, Brown LF, Detmar M VEGF-A induces tumor and sentinel lymph node lymphangiogenesis and promotes lymphatic metastasis. J Exp Med 2005;201(7):1089-99.

33. Maeda K, Chung Y, Ogawa LY, Kang SM, Ogawa M, Takatsuka S et al. Prognostic value of vascular endothelial factor expression in gastric carcinoma. Cancer 1996;77:858-63.

34. Decaussin M, Sartelet H, Robert C, Moro D. Claralz C, Brmabilla C et al. Expression of vascular endothelial growth factor (VEGF) and its receptors in non small cell lung carcinoma: correlation with angiogenesis and survival. J Pathol 1999;188:369-77.

35. Hwang C, Heath EL. Angiogenesis inhibitors in the treatment of prostate cancer. J Hematol Oncol 2010;3:26.

36. Maeda T, Matsumura $S$, Hiranuma $H$, Jikko A, Furukawa $S$, Ishida $T$, Fuchihata $\mathrm{H}$. Expression of $\mathrm{p} 53$ and vascular endothelial factor in human oral squamous cell carcinoma: Its association with tumor progression and p53 status. J Clin Pathol 1998;51(10):771-5.

37. Lim JJ, Kang S, Lee MR, Pai HK, Yoon HJ, Lee JI, Hong SP, Lim CY. Expression of vascular endothelial growth factor in salivary gland carcinomas and its relation to $\mathrm{p} 53, \mathrm{~K}-67$ and prognosis. J Oral Pathol Med 2003;32(9):552-61.

38. Lequerica-Fernández P, Astudillo A, De Vicente JC. Expression of vascular endothelial growth factor in salivary gland carcinoma correlates with lymph node metastasis. Anticancer Res 2007;27:3661-6.

39. Lee SK, Kwon MS, Lee YS, Choi SH, Kim SY, CHo KJ, Nam SY. Prognostic value of expression of molecular markers in adenoid cystic cancer of the salivary gland compares with lymph node metastasis: a retrospective study. World J Surg Oncol 2012;10:266-80.

40. Ou Yang K, Liang J, Huang ZQ. Association of clinicopathologic parameters with the expression of inducible nitric oxide synthase and vascular endothelial growth factor in mucoepidermoid carcinoma. Oral Dis 2011;17:590-6.

41. Faur AC, Lazar E, Cornianu M. Vascular endothelial growth factor (VEGF) expression and microvascular density in salivary gland tumors. APMIS 2013;122:418-26.

42. Pammer J, Weninger W, Mildner M, Burian M, Wojta J, Tschachler E. Vascular endothelial growth factor is constitutively expressed in normal human salivary glands and is secreted in the saliva of healthy individuals. J Pathol 1998;186(2):186-91.

43. Faria PR, Lima RA, Dias FL, de Faria PAS, Eisenberg ALA, DoNascimento Souza KC, Cardovo SV, Loyola AM. Vascular endothelial growth factor and tymidine phosphorylase expression in salivary gland tumors with distinct metastatic behavior. J Oral Pathol Med 2011;40:456-9.

44. Salzman R, Stárek I, Kučerová L, Skálová A, Hoza J. Neither expression of VEGF-C/D nor lymph vessel density supports lymphatic invasion as the mechanism responsible for local spread of recurrent salivary pleomorphic adenoma. Virchows Arch 2014;464:29-34.

45. Soares AB, De Araujo VC, Juliano PB, Altemani A. Angiogenic and lymphangiogenic microvessel density in recurrent pleomorphic adenoma. J Oral Pathol Med 2009;38(8):623-9.

46. Soares AB, Altemani A, De Oliveira TR, de Oliveira Fonseca Rodrigues F, Ribeiro-Silva A, Soave DF, Passador-Santos F, Brum ST, Napimoga $\mathrm{MH}$, de Araújo VC. Comparison of the blood and lymphatic microvessel density of pleomorphic adenoma and basal cell adenoma. Clin Med Insights Pathol 2015;8:17-21.

47. Teymoortash A, Werner JA. Tissue that has lost its track: Warthin's tumour. Virchows Arch 2005;446(6):585-8.

48. Koukourakis MI, Giatromanolaki A, Sivridis E, Simopoulos C, Gatter $\mathrm{KC}$, Harris AL, Jackson DG. LYVE-1 immunohistochemical assessemnt of lymphangiogenesis in endometrial and lung cancer. J Clin Pathol 2005;58(2):202-6.

49. Tanigawa N, Kanazawa T, Satomura K, Hikasa Y, Hashida M, Muranishi $\mathrm{S}$, Sezaki H. Experimental study on lymphatic vascular changes in the development of cancer. Lymphology 1981;14(4):149-54.

50. Williams CSM, Leek RD, Robson AM, Banerji S, Prevo R, Harris AL, Jackson DG. Absence of lymphangiogensis and intratumoral lymph vessels in human metastasic breast cancer. J Pathol 2003;200(2):195206.

51. Agarwal B, Saxena R, Morimiya A, Mehrotra S, Badve S. Lymphangiogenesis does not occur in breast cancer. Am J Surg Pathol 2005;29(11):1449-55.

52. Baek SK, Jung KY, Lee SH, Woo JS, Kwon SY, Chung EJ, Kim TH, Chae YS.Prognostic significance of vascular endothelial growth factor-C expression and lymphatic vessel density in supraglottic squmaous cell carcinoma. Laryngoscope 2009;119(7):1325-30.

53. Franchi A, Gallo O, Massi D, Baroni G, Santucci M. Tumor lymphangiogenesis in head and neck squamous cell carcinoma. A morphometric study with clinical correlations. Cancer 2004;101(5):973-8.

54. Maula SM, Luukkaa M, Grenman R, Jackson D, Jalkanen S, Ristamäki $R$. Intratumoral lymphatics are essential for the metastatis spread and prognosis in squamous cell carcinoma of the head and neck region. Cancer Res 2003;63(8):1920-6.

55. Muñoz-Guerra MF, Marazuela EG, Martín-Villar E, Quintanilla M, Gamallo C. Prognostic significance of intratumoral lymphangiogenesis in squamous cell carcinoma of the oral cavity. Cancer 2004;100(3):553-60.

56. Maby-El Hajjami H, Petrova TV. Developmental and pathological 
lymphangiogenesis: from models to human disease. Histochem Cell Biol 2008;130(6):1063-78.

57. Leu AJ, Berk DA, Lymboussaki A, Alitalo K, Jain RK. Absence of functional lymphatics within a murine sarcoma: a molecular and functional evaluation. Cancer Res 2000;60(16):4324-7.

58. Padera TP, Stoll BR, Tooredman JB, Capen D, di Tomaso E, Jain RK. Pathology: Cancer cells compress intratumour vessels. Nature 2004:427(6976):695.

59. Skobe M, Detmar M. Structure, function and molecular control of the skin lymphatic system. J Investig Dermatol Symp Proc 2000;5(1):14 9.
60. Kerjaschki D. The crucial role of macrophages in lymphangiogenesis. J Clin Invest 2005;115(9):2316-19.

61. Björndahl MA, Cao R, Burton JB, Brakenhielm E, Religa P, Galter D, Wu L, Cao Y. Vascular endothelial growth factor-a promotes peritumoral lymphangiogenesis and lymphatic metastasis. Cancer Res 2005;65(20):9261-8.

62. Honda K, Kashima K, Daa T, Yokoyama S, Nakayama I. Clonal analysis of the epithelial component of Warthin's tumor. Hum Pathol 2000;31(11):1377-80.

63. Rabia AB, Ebru LS, Tuba K, Didar G, Gulhan O, Cengiz O. Warthin's tumor: An unknown pathogenesis: A neoplasm or a reactive hyperplasia? Indian J Pathol Microbiol 2015;58(1):7-11. 